\title{
Numerical simulation of water waves impact on near-shore defensive structures
}

\author{
Marc BATLLE MARTIN ${ }^{1}$, Grégory PINON ${ }^{1}$, Julien REVEILLON ${ }^{2}$
}

1. Laboratoire Ondes et Milieux Complexes (LOMC), UMR 6294, CNRS - Normandie Université - UNIHAVRE, 76600 Le Havre, France.

gregory.pinon@univ-lehavre.fr

2. Complexe de Recherche Interprofessionnel en Aérothermochimie (CORIA), UMR 6614, CNRS - Université de Rouen et Institut des Sciences Appliquées, 76801 SaintEtienne du Rouvray, France.

\begin{abstract}
:
This paper aims to give initial guidelines for oscillating water column design using computational fluid dynamics. OpenFOAM have been used to analyse, first, the feasibility to reproduce an irregular sea state. Historical data from a near-shore buoy on Saint-Jean-de-Luz has been used for this purpose. Also, an Oscillating Water Column large scale geometry has been simulated facing regular waves. Strengths and weaknesses regarding the numerical tool performance are presented and settle a point of departure to reproduce a more realistic storm event.
\end{abstract}

\section{Keywords:}

Coastal engineering, Oscillating Water Column, Computational fluid dynamics

\section{Introduction}

Actual climate debate has focused on energy generation and more precisely, on efficiency and feasibility of large device producing clean energy at a national level. This green energy dependency evokes the importance of a diversified and versatile system to fulfill the dynamic population needs. By means of this current, there is a rising part of the population that highlights the great source of clean energy that oceans could provide. The variety of cyclic processes occurring at sea, such as tidal, thermal currents or water waves, makes evident this rising interest.

Nevertheless, these phenomena may be an opportunity or an issue. In terms of waves, they can cause important damages and losses in the coastlines due to their highly energetic impacts, or conversely, they can be seen as a huge source when looking at their potential energy properties. Therefore, we can take advantage of these two facts together in a technical way by means of installing wave energy devices onto coastal protection structures. Oscillating Water Column (OWC) is a possible concept, protecting the shoreline and generating clean energy at the same time. This engineering structure has been already tested in Pico island (Portugal), Mutriku (Spain) or Islay (UK). Multiple studies have focused on this kind of devices from an experimental point of view 


\section{Thème 5 - Énergies et ressources marines}

(GOUAUD et al., 2010; ALLSOP et al., 2014), or using different numerical approaches (DELAURÉ \& LEWIS, 2003; DIMAKOPOULOS et al., 2015; ELHANAFI et al., 2016), among others.

Experience from OWC prototypes deployments has however shown that is easy to underestimate wave loadings on this kind of devices. Direct wave loadings have been a matter of interest for many years and reasonably good prediction methods are available (GODA, 2010). But these are proposed and validated for simple structures like caisson breakwaters and they need to be adapted for more complex structures as the OWC. Here the oscillating behavior between the interior and the exterior fluid can lead to undesired stress on the structure carapace. Furthermore, the overturning of some waves during an irregular sea state leads to impulsive loads on exposed part of the structure.

This paper aims to give insights on these matters using Computational Fluid Dynamics (CFD) approach by means of the open-source numerical toolbox OpenFOAM. The present work is organized in four sections, where; firstly, the numerical model core equations are presented. Secondly, an irregular sea state is reproduced numerically on deep water conditions with a flat bottom. Next a mesh sensitivity and a qualitative analysis of the structure undergoing a fluid oscillation problem is studied on Section 4. Finally, the structure is evaluated facing a regular sea state.

\section{Numerical tool}

In this section, the numerical model assumptions and core equations are introduced. A multiphase solver is chosen using a finite volume spatial discretization and Volume Of Fluid (VOF) to track the free surface between phases, namely; air and water. The NavierStokes equation ensures the momentum conservation at every cell, taking the form:

$\frac{\partial \rho u}{\partial t}+\nabla \cdot(\rho u u)=-\nabla p+\rho g+\mu \nabla^{2} u$

where $\rho$ is the phase density, $\mathrm{u}$ is the cell centred velocity vector, $p$ is a relative pressure under the incompressible assumption and $\mu=\rho v$ the dynamic molecular viscosity, $v$ is the kinematic viscosity. The problems presented in this scope are assumed to be inertial driven flows and, thus, the surface tension effects will be neglected for the sake of simplicity. Secondly, to ensure the mass conservation the continuity equation for incompressible flows takes the general form:

$\nabla \cdot u=0$

In order to model two phases a new variable, namely liquid volume fraction $\alpha$, is introduced as:

$\alpha=\frac{\rho-\rho_{\text {air }}}{\rho_{\text {water }}-\rho_{\text {air }}}$

taking values of 1 for water and 0 for air. Similarly, as the mass continuity equation a transport equation for the liquid volume fraction reads: 


\section{XVIèmes Journées Nationales Génie Côtier - Génie Civil \\ Le Havre 2020}

$\frac{\partial \alpha}{\partial t}+\nabla \cdot(\alpha \boldsymbol{u})=0$

\section{Irregular sea state}

In this section the objective is to reproduce numerically an irregular sea state and analyse the possible limitations. In this work the irregular sea state will be modelled, initially, using a Join North Sea Wave Observation Project JONSWAP spectrum as a wind waves fully developed sea. The calibration of the spectrum will be based on real data from CANDHIS (Centre d'Archivage National de Données de Houle In Situ) regarding the buoy $1.2 \mathrm{~km}$ away from Saint-Jean-de-Luz near-shore (see table 1).

Table 1. Buoy details, extracted from CANDHIS.

\begin{tabular}{ll}
\hline Buoy reference & 06403 \\
Observation time frame & 6 years \\
Latitude & $43^{\circ} 24,500^{\prime} \mathrm{N}$ \\
Longitude & $01^{\circ} 40,900^{\prime} \mathrm{W}$ \\
Depth $[\mathrm{m}]$ & 20 \\
Tidal range $[\mathrm{m}]$ & 3.75 \\
\hline
\end{tabular}

In this location, the highest probability of occurrence is around $90 \%$ for significant wave height of $1 \mathrm{~m}$ and a wave peak period of $9 \mathrm{~s}$. Thus, this parameters with a peak enhancement factor of 3.3 define the spectrum presented in figure 1 and will be employed in our simulations.
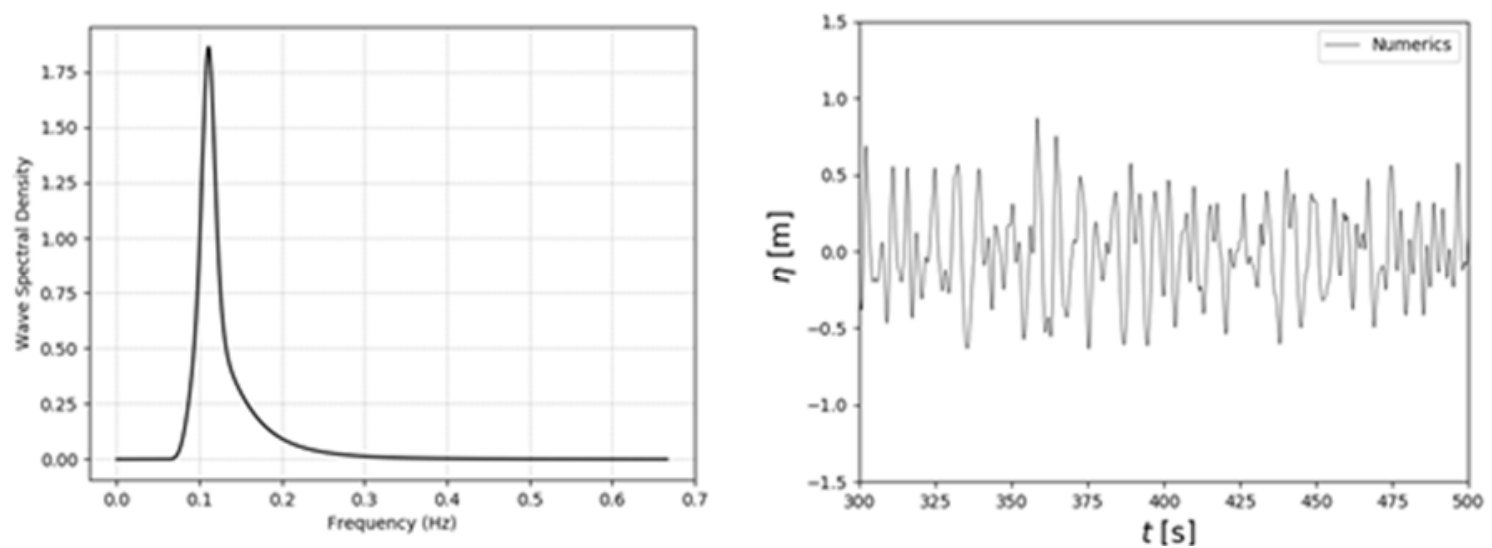

Figure 1. (left): JONSWAP spectrum (Hs = $1 \mathrm{~m}, \mathrm{Tp}=9 \mathrm{~s}$ ). (right): Numerical free surface elevation over time.

To do so, a rectangular domain of $150 \mathrm{~m}$ length and $25 \mathrm{~m}$ high will be used to model a 2D configuration of a wave flume. An orthogonal structured mesh is employed for the spatial discretisation. An initial water depth of $20 \mathrm{~m}$ is chosen according to the buoy 


\section{Thème 5 - Énergies et ressources marines}

conditions. The boundary conditions are defined as; open for the top edge, wall for the bottom, an absorbing boundary at the end of the numerical wave flume and a static wave generation for the inlet as the left boundary.

This type of inlet imposes velocities and free surface elevation following the chosen wave theory. Here the irregular theory employs a linear superposition of first order Stokes waves for a given number of components $N_{s}$, where the free surface is calculated as:

$\eta(x, t)=\sum_{i=1}^{N_{s}} \frac{H_{i}}{2} \cos \left(k_{i} x-\omega_{i} t+\psi_{i}\right)$

where $H_{i}$ is the wave height, $k_{i}$ the wave number, $\omega_{i}$ the angular frequency and $\psi_{i}$ the wave phase. Similarly, the velocities will be calculated using a superposition of the linear theory for every wave. The spectrum presented in figure 1 is now numerically integrated and divide it into slices of equal frequency within the frequency limits $f p / 2$ and $3 f$ (where $f p=$ peak frequency). A discrete function of $N_{s}$ frequencies is obtained and introduced on the wave generation inlet. The wave phases are chosen randomly.

Using numerical wave gauges the free surface can be extracted (see figure 1). The calculated significant wave height $H s=1.05 \mathrm{~m}$ and the maximum wave height $H m a x=2.05 m$ are in agreement with the input data. The spectral density is estimated from the temporal series using the Welch's method (WELCH, 1967) by averaging over 12 periodogram spectrums estimates (see figure 2).

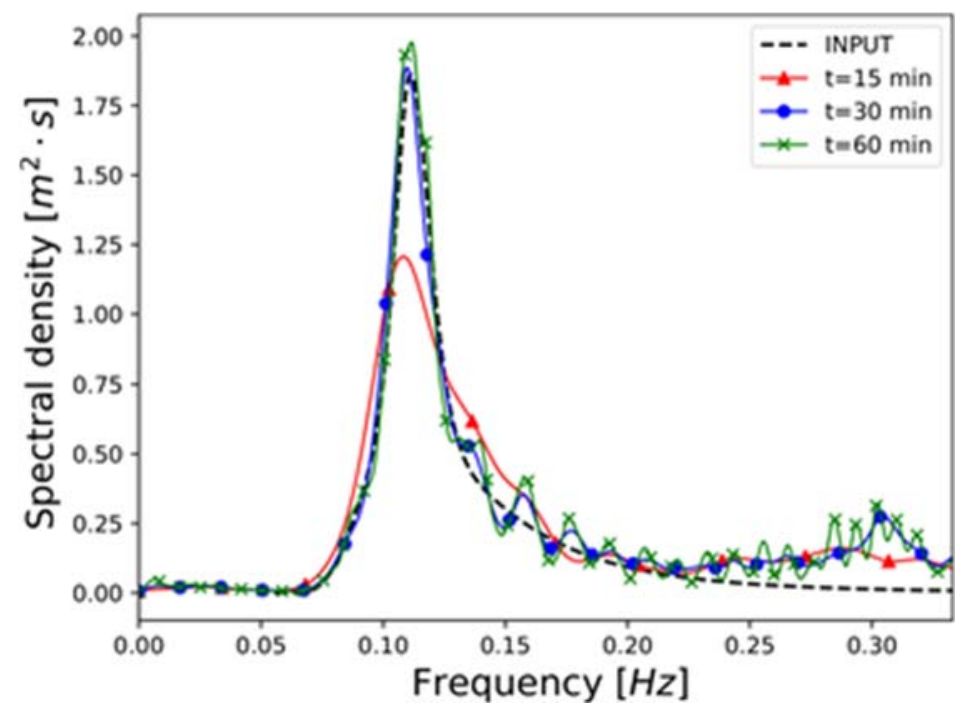

Figure 2. Developing spectrum. $H s=1 \mathrm{~m}$ and $T p=9 \mathrm{~s}$.

A fairly good agreement is found in terms of peak frequency and shape for this sea-state conditions. The physical time length is a key parameter to fully develop the irregular sea state, which, in this situation is achieved after $\mathrm{t}=30 \mathrm{~min}$. Smaller wave periods, from $\mathrm{T} \leq 5 \mathrm{~s}$ or $\mathrm{f} \geq 0.2 \mathrm{~Hz}$, are over estimated here. This could be caused by some reflection 


\section{XVİ̀mes Journées Nationales Génie Côtier - Génie Civil \\ Le Havre 2020}

from the outlet absorbing boundary, which is meant to be more suitable for shallow water conditions.

The results presented above employed a uniform mesh with cells aspect ratio (cell width/ cell height) of 4 and $\mathrm{Hs} /$ cell height=16. An adjustable time step was used fixing a maximum Courant number of 0.65 . Using the computing resources provided by CRIANN (Centre Régional Informatique et d'Applications Numériques de Normandie) the simulation was runned in parallel over 56 processors and it took $5 \mathrm{~h}$ to simulate $15 \mathrm{~min}$.

\section{The oscillating problem}

This section focuses on a qualitative analysis of the Oscillating Water Column working behaviour on a simplified case. This study aims to evaluate the mesh sensitivity undergoing a sloshing-type situation which can be related to a run-up/run-down process. To do so, the fluid starts from a static position where there is a hydrostatic difference $\Delta h$ between the inside and the outside of the chamber, see figure 3. After the initialization the water will be flowing inside the chamber rising the $h_{\text {int }}$ level and pushing the air out from the structure. Once the interior free surface reaches the highest level the water will flow now out from the chamber pulling air inside the structure.
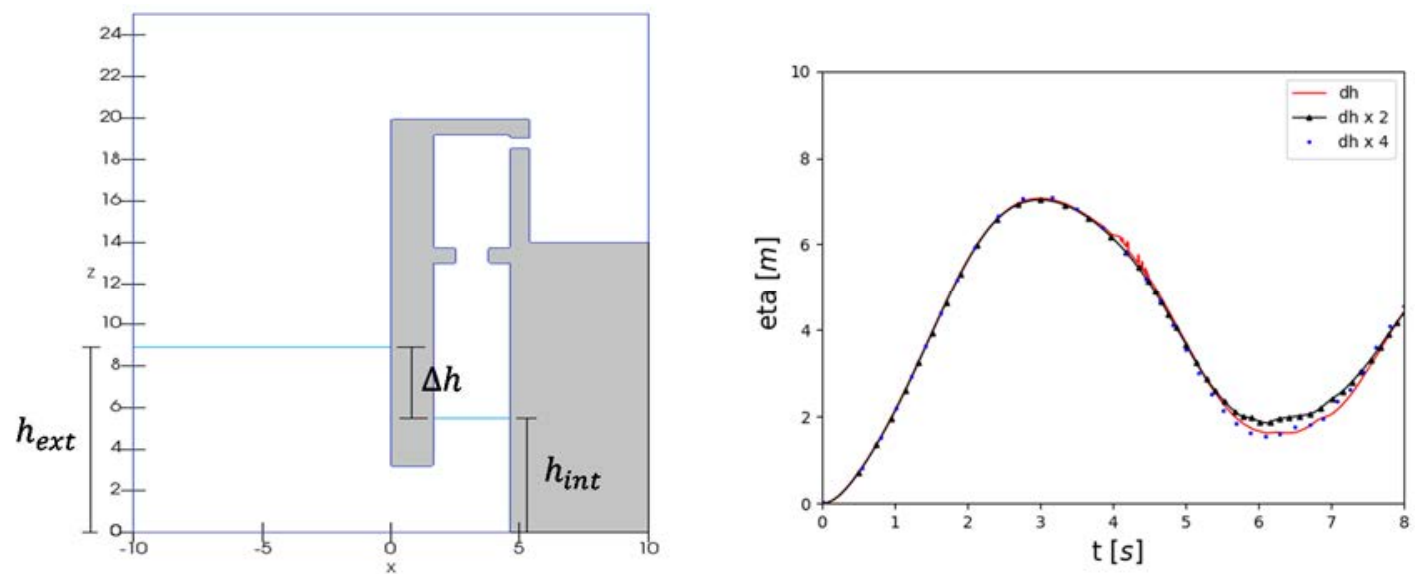

Figure 3. (left): The oscillating problem. (right): Free surface elevation convergence inside the chamber.

A convergence study has been carried out setting $h_{\text {int }}=4.5 \mathrm{~m}$ and $\Delta h=5 \mathrm{~m}$, see figure 3. The free surface elevation for the first oscillation inside the chamber is plotted against time for three different mesh refinements. The cell size for the finest mesh is $d h=5 \mathrm{~mm}$. A good convergence is achieved in this extreme situation regarding the spatial discretisation and even the coarser mesh $(d h=62 \mathrm{~mm})$ is acceptable for this purpose. During the study of MEDINA-LOPEZ et al., (2015), it was mentioned the importance of the carapace lower part geometry, which may induce pressure drops and, eventually, cavitation. During the first oscillating, the flow entering the chamber close to the carapace 


\section{Thème 5 - Énergies et ressources marines}

edge creates a recirculation zone which drops the pressure as it is observable on figure 4. Regarding a pressure temporal series on the interior boundary wall of the carapace, see figure 4 , it is observable this phenomenon as the blue spot.
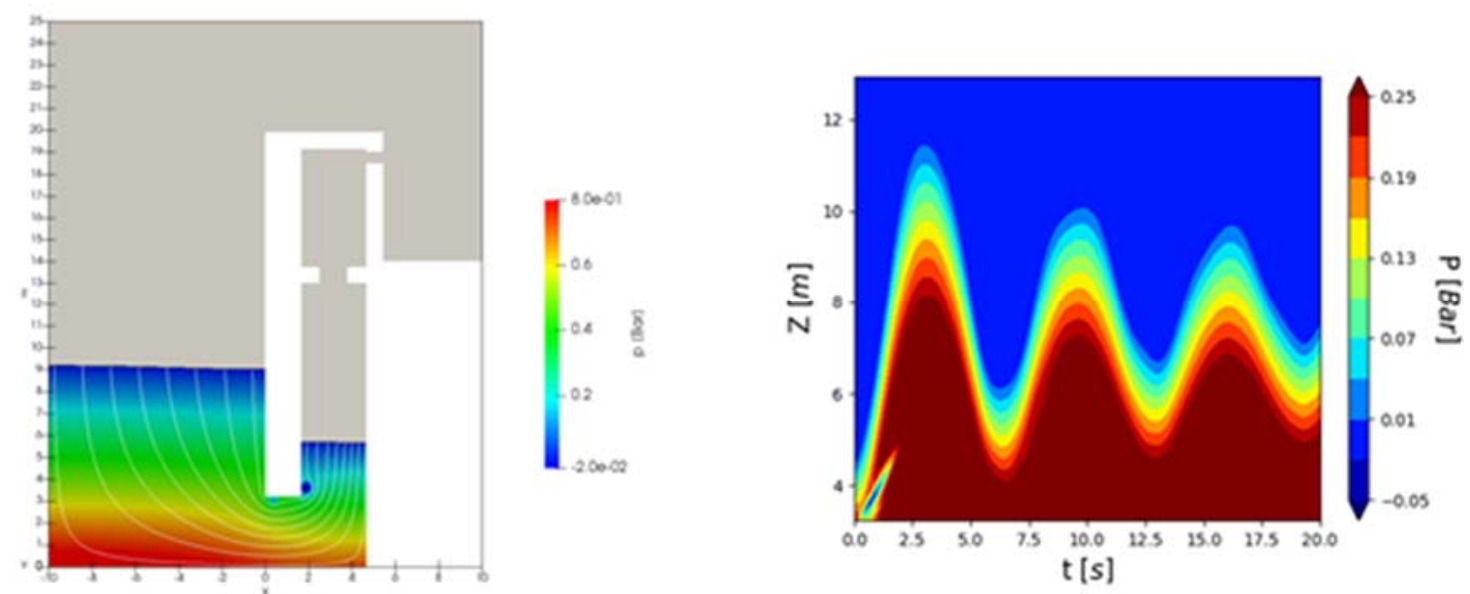

Figure 4. (left): Pressure fields and streamlines at $t=0.7$ s. (right): Pressure evolution on the interior carapace wall.

\section{OWC regular waves}

This section presents the behaviour of the OWC device facing a regular wave train. To do so, a 2D $40 \mathrm{~m}$ long numerical wave flume with a flat bottom is used. A first order Stokes theory is introduced on the inlet wave generator, similarly as in section 1 . The wave parameters are selected here as; $\mathrm{H}=1 \mathrm{~m}, \mathrm{~T}=4 \mathrm{~s}$ and the initial water depth is $8 \mathrm{~m}$. The simulation runs for $25 \mathrm{~s}$ seconds allowing the first waves to interact with the structure.

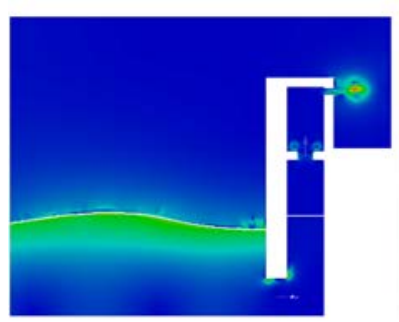

$t=12,8 \mathrm{~s}$

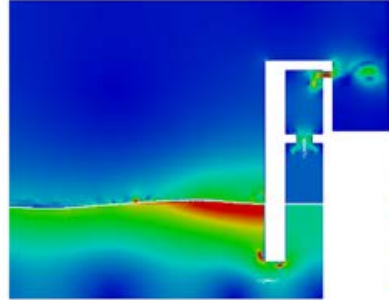

$t=14 \mathrm{~s}$

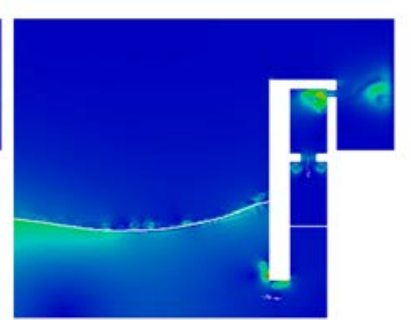

$t=15 s$
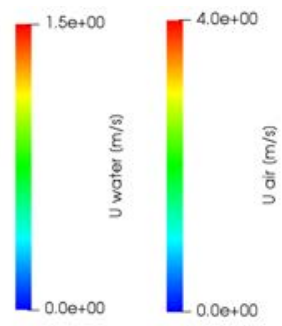

Figure 5. Velocity fields during a run up and down process.

Figure 5 presents three relevant instants, namely; the run-down when the free surface reaches the highest level inside the chamber and the exterior free surface reaches the minimum. An intermediate instant $(\mathrm{t}=14 \mathrm{~s})$ where the fluid inside and outside the chamber have similar free surface elevations. And, the run-up, when the interior has a minimum elevation and the wave reaches a maximum on the exterior of the carapace. The velocity 


\section{XVIèmes Journées Nationales Génie Côtier - Génie Civil \\ Le Havre 2020}

fields are presented with different ranges for air and water to be more representative. It is observable the air flowing on the turbine location, especially on the second snapshot were velocities up to $2-3 \mathrm{~m} / \mathrm{s}$ are reached. The recirculation zones mentioned in section 4 on the bottom of the carapace is also presented here.

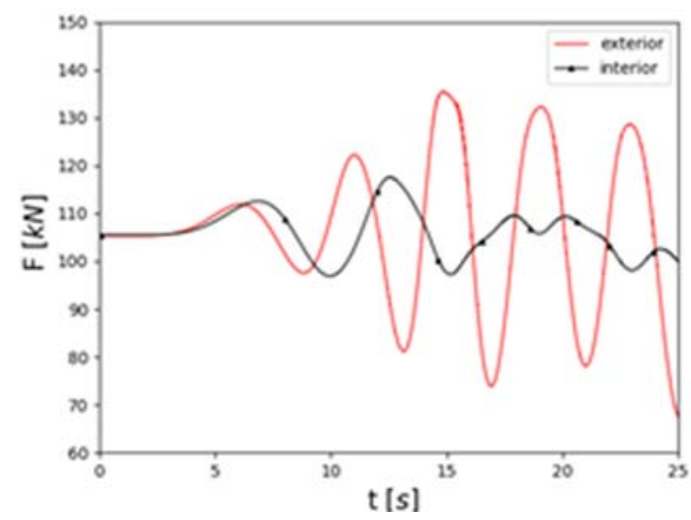

Figure 6. Force on the exterior and interior of the structure carapace.

Regarding the resultant force on the carapace, both from the interior and from the exterior on figure 6. Both signals are out of phase for during the first oscillation. When the exterior fluid reaches a maximum level, the interior of the chamber has a minimum. This is clearly seen for example at $t=15 \mathrm{~s}$. Further analysis must be carried out in this direction, specially, for plunging waves where the structure is expected to work under limit conditions.

\section{Conclusions}

The CFD tool OpenFOAM has demonstrated in this paper the capabilities to reproduce an irregular sea state with low amplitudes, following a JONSWAP distribution. The simulation time has shown to be an important factor for fully developed sea states and now further analysis on more extreme conditions are envisaged.

In the other hand, an OWC full scale geometry has been tested on an oscillatory flow induced by hydrostatic pressure difference between the interior and exterior of the chamber. The shape of the carapace lower part has been identified as an important point of design as it may induce recirculation zones. Finally, the OWC geometry has been tested facing a regular wave train. Regarding the loads on both sides of the carapace present momentaneous situations where they are out of phase avoiding an equilibrium state.

\section{References}

ALLSOP W., BRUCE T., ALDERSON J., FERRANTE V., RUSSO V., VICINANZA D., KUDELLA M. (2014). Large scale tests on a generalised oscillating water column wave energy converter. Proceedings of the HYDRALAB IV Joint User Meeting, 2-4 July 2014, Lisbon, Portugal, 7 p. 


\section{Thème 5 - Énergies et ressources marines}

DELAURÉ Y.M.C., LEWIS A. (2003). 3D hydrodynamic modelling of fixed oscillating water column wave power plant by a boundary element methods. Ocean Engineering, Volume 30(3), pp 309-330. https://doi.org/10.1016/S0029-8018(02)00032-X

DIMAKOPOULOS A., COOKER M., MEDINA-LOPEZ E., LONGO D., PINGUET R. (2015). Flow characterisation and numerical modelling of OWC wave energy converters. $11^{\text {th }}$ European Wave and Tidal Energy Conference series, EWTEC 2015, 6-11 September 2015, Nantes, France.

ELHANAFI A., FLEMING A., MACFARLANE G., LEONG Z. (2016) Numerical energy balance analysis for an onshore oscillating water column-wave energy converter. Energy, Volume 116, Part 1, pp 539-557. https://doi.org/10.1016/j.energy.2016.09.118

GODA Y. (2010). Random seas and design of maritime structures. Advanced Series on Ocean Engineering, Vol. 33, Random Seas and Design of Maritime Structures, 732 p. https://doi.org/10.1142/7425

GOUAUD F., REY V., PIAZZOLA J., VAN HOOFF R. (2010). Experimental study of the hydrodynamic performance of an onshore wave power device in the presence of an underwater mound. Coastal Engineering, Vol. 57(11-12), pp 996-1005. https://doi.org/10.1016/j.coastaleng.2010.06.003

MEDINA-LOPEZ E., ALlSOP W., DIMAKOPOUlOS A., BRUCE T. (2015). Conjectures on the failure of the OWC breakwater at Mutriku. Coastal Structures and Solutions to Coastal Disasters Joint Conference, Boston, Massachusetts, September 9-11, 2015, pp 592-603. https://doi.org/10.1061/9780784480304.063

WELCH P. (1967). The use of fast Fourier transform for the estimation of power spectra: A method based on time averaging over short, modified periodograms. IEEE Transactions on Audio and Electroacoustics, Vol. 15(2), pp. 70-73. https://doi.org/10.1109/TAU.1967.1161901 